\title{
EPS Sensor Torsion Bar Design and Structure Analysis
}

\author{
Shu-juan Fang ${ }^{1, a}$ and Qing-tao Lv ${ }^{2}$ \\ ${ }^{1}$ Hulunbuir University Mining College, Inner Mongolia Hulunbuir, China \\ ${ }^{2}$ Hella Shanghai Electronics Co.,Ltd.,Shanghai, China
}

\begin{abstract}
Torsion bar design is very important on Electrical power steering(EPS) development. The mathematical model and structure for torsion bar are developed, and the torsion bar outer spline is cancelled based on the automotive parameters. This kind of structure leads to cost down and time saving on torsion bar manufacturing process. The 3D model and finite element on sub-EPS(torsion bar, input shaft, output shaft) are developed, and then do the contact nonlinear analysis based on interference between torsion bar and output shaft. The EPS structure and test reliability according to function test and durability test are verified and the test results are passed.
\end{abstract}

\section{Introduction}

Since the first Electrical Power Steering (EPS) was developed in the 1980s, the assembly rate of EPS was increased by $8 \%-10 \%$ annually. Nowadays, EPS have been installed in most of the automotives all over the world, and around $80 \%$ automotives have EPS in United States, Japan and other developed countries $[1,2]$. EPS is very important in energy saving, emission reduction in technological progress of the entire automotive industry. In parallel, the requirements for the key components of the electrical power steering system are also increasing.

\section{Classification of EPS system}

EPS is classified as following based on different assembly locations in the vehicles: column type EPS (C-EPS), pinion type EPS (P-EPS) and rack type EPS (R-EPS). C-EPS is mainly installed under the steering wheel, which is suitable for Class A0 and Class A vehicles. Normally, EPS can realize more than 10 Newton on steering assist. P-EPS is mainly installed in the front cabin near the rack position, which is suitable for Class B or some of Class C vehicles. Normally, P-EPS can realize more than 20 Newton on steering assist. R-EPS is mainly installed near the engine and parallel with rack, which is suitable for $\mathrm{C}$ or $\mathrm{C}$ above vehicles or trucks. Normally, R-EPS can realize more than 30 Newton on steering assist. In addition, in order to make the steering system being forced uniformly, the P-EPS motor and deceleration mechanism are assembled separately, which is called as double pinion type EPS(DP-EPS) [3]. Details are shown in Figure 1.

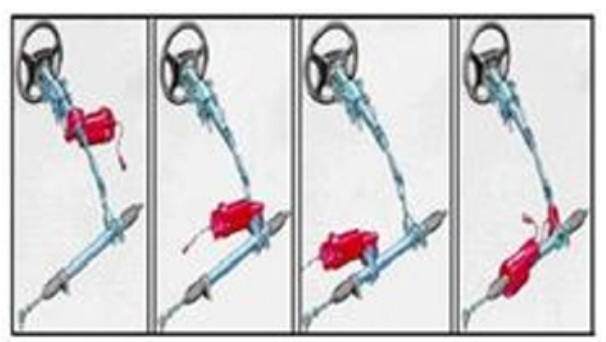

Figure 1. Classification of EPS

\section{Principle of electric power steering system}

EPS mainly includes in the following 4 parts: Electrical Control Unit (ECU), motor, sensor and deceleration mechanism $[4,5]$. Among all the parts, the torsion bar is a very important part of the deceleration mechanism which converts the torque of the human hand into the mechanical angle, and then EPS sensor send out signal after testing the angle. When the automotive is started up, EPS ECU does self-test firstly, including power supply voltage signal test, engine signal test, speed signal test,

\footnotetext{
a Corresponding author: $32577140 @ q q . c o m$
} 
torque signal test, etc. After all the tests successfully, then ECU drives the motor to realize the steering assist according to the assist curve.

\section{Torsion bar design}

In order to be assembled easily, the torsion bar in the electric power steering system is usually designed as a slender rod structure by arc in the middle, and an outer spline at one end and a pinhole near the other end. The spline side of the torsion bar is pressed into the output shaft by a hydraulic press, and then a torque sensor is installed. After the torque midpoint of the EPS system is adjusted, the input shaft is installed, and the pin is punched into the pinhole of the input shaft and the torsion bar.

However, in order to save the processing cost and simplify the processing steps, a torsion bar without spline is designed. Torque is transmitted by the interference fit between the torsion bar and the output shaft. The radial contact pressure is generated by the interference, and torque and axial force are transmitted by the friction force generated by the interference.

The torsion bar is regarded as a rod with the same section diameter to simplify the calculation. The torsion deformation of the rod is studied by using the principle of material mechanics, and the stiffness formula of the rod is obtained as follows [6].

$$
\varphi=\frac{\mathrm{TL}}{\mathrm{GI}_{\rho}} \times \frac{180^{\circ}}{\pi}
$$

$\varphi$ is the torsion angle (degree), $\mathrm{T}$ is the torsion moment on the section of the rod, $\mathrm{L}$ is the length of the $\operatorname{rod}, \mathrm{G}$ is the shear modulus of the material, $I_{\rho}$ is the polar inertia moment, and $\mathrm{GI}_{\rho}$ is the torsion stiffness. For solid circular rods, the $I_{\rho}$ moments are as follows.

$$
\mathrm{I}_{\rho}=\frac{\pi \mathrm{d}^{4}}{32}
$$

Therefore, the torque angle $\varphi$ is as follows.

$$
\varphi=\frac{T L}{G I_{\rho}}=\frac{T \times L \times 32}{G \times \pi \times d^{4}} \times \frac{180^{\circ}}{\pi}
$$

When the rod is subjected to torque $\mathrm{T}$, the shear stress is calculated as follows.

$$
\tau=\frac{T}{W_{p}}
$$

Then,

$$
\tau=\frac{T}{W_{p}}=\frac{T \times 16}{\pi \times d^{3}}
$$

Strength condition

$$
\tau_{\max } \leq[\tau]
$$

$[\tau]$ is the maximum allowable shear stress for the materials [7].

The target vehicle type is A0. The torque applied to the torsion bar by turning the steering wheel manually is normally below $10 \mathrm{Nm}$. If the safety factor is 1.5 , then $\mathrm{T}_{\max }=10 \mathrm{Nm} \times 1.5=15 \mathrm{Nm}$. The torsion bar material is spring steel $60 \mathrm{Si}_{2} \mathrm{MnA}, \mathrm{G}=79000 \mathrm{MPa},[\tau]=590 \mathrm{MPa}$. In the formula (6), $d=5.01 \mathrm{~mm}$ can be obtained. Then take $\mathrm{d}_{2}=5.5 \mathrm{~mm}$.

Generally, the mechanical limit angle of the torsion bar of EPS deceleration mechanism is \pm 4 degrees, so the working torsion angle of the torsion bar is set to \pm 6 degrees, which can meet the measurement range of most torque sensors. If put the $\varphi=6^{\circ}$ and $\mathrm{d}_{2}=5.5 \mathrm{~mm}$ into formula (3), the working length can be calculated $L_{a}=$ $22.3 \mathrm{~mm}$, then choose as $22 \mathrm{~mm}$. End diameter is recommended as $\mathrm{d}_{1}=\mathrm{d}_{2} \times(1.2 \sim 1.3)=(7.2 \sim 7.8) \mathrm{mm}$, then $\mathrm{d}_{1}=7.8 \mathrm{~mm}$ is taken.

The transition part from the end of the torsion bar to the diameter of the working length is called as the transition section. The size of the transition section is gradually changing so as to minimize the stress concentration.

The transition section is $\mathrm{L}_{\mathrm{g}}=\frac{\mathrm{L}_{2}-\mathrm{L}_{1}}{2} \approx \frac{\mathrm{d}_{1}-\mathrm{d}_{2}}{2 \tan 15^{\circ}}=$ $3.4 \mathrm{~mm}$.

The transition section radius $\mathrm{R}=\frac{\mathrm{L}_{\mathrm{g}}^{2}}{\mathrm{~d}_{1}-\mathrm{d}_{2}}+\frac{\mathrm{d}_{1}-\mathrm{d}_{2}}{4}=$ $6.87 \mathrm{~mm}$, take as $\mathrm{R}=6.9 \mathrm{~mm}$.

In addition, the transition section is generally divided into effective length and non effective length. The effective length is as following

$\mathrm{L}_{\mathrm{e}}=\frac{\mathrm{Lg}}{3}\left[\frac{\mathrm{d}_{2}}{\mathrm{~d}_{1}}+\left(\frac{\mathrm{d}_{2}}{\mathrm{~d}_{1}}\right)^{2}+\left(\frac{\mathrm{d}_{2}}{\mathrm{~d}_{1}}\right)^{3}\right]=2.06 \mathrm{~mm}$, take as $\mathrm{L}_{\mathrm{e}}=$ $2 \mathrm{~mm}$

Based on the above analysis, the length of the middle segment can be obtained $\mathrm{L}_{1}=\mathrm{L}_{\mathrm{a}}-2 \times \mathrm{L}_{\mathrm{e}}=18 \mathrm{~mm}$.

Then set the middle parts length as $L_{d}=20 \mathrm{~mm}$

So, the total length is as following

$$
\mathrm{L}=\mathrm{L}_{1}+2 \times \mathrm{L}_{\mathrm{g}}+2 \times \mathrm{L}_{\mathrm{d}}=64.8 \mathrm{~mm}
$$




\section{Structure analysis of torsion bar}

In general, mechanical design is based on experience, but for the complex structure with strict safety requirements, the stress and strain analysis is needed [8,9]. In addition, it is difficult to directly measure the stress and strain on the two contact surfaces of the interference fit between the torsion bar and the output shaft, and there is alternating load at this kind of contact surface. Therefore, it is necessary to obtain the appropriate interference fit parameters by theoretical analysis.

\subsection{Establish a geometric model}

Because of the complexity of the model, the 3D model (input shaft, torsion bar, output shaft) is established by 3D software, and then it is transferred to the intermediate format file and imported into the finite element analysis software. The torsion bar and the input shaft are fixed by pins. When doing the finite element analysis, the nodes of the outer diameter of the torsion bar and the inner diameter of the input shaft can be bind together, so the finite element model of the pin is no needed. That means, the 3D model of the pin need not to be imported. It saves the workload of dividing grid and saves computing time.

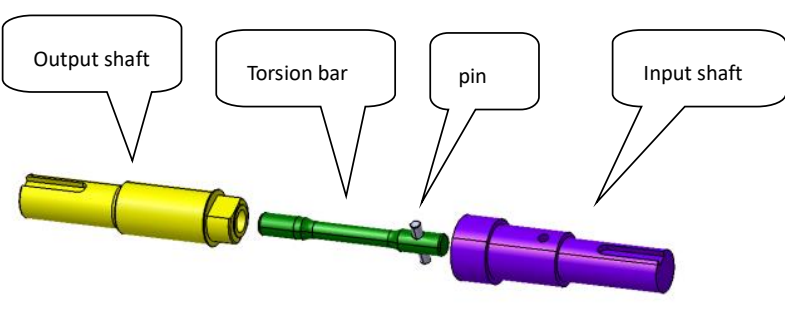

Figure 2. EPS sub-assembly (input shaft, output shaft, torsion bar, pin)

\subsection{Mesh}

The traditional linear analysis method divides the contact surfaces into meshes with the same nodes and assumes that two contact objects transmit contact force through the nodes. This method needs to know the exact contact location in advance so as to set boundary conditions. However, this linear analysis method can not simulate the real friction state [10-12]. To reflect the real status of the torsion bar accurately, the strain analysis results of the torsion bar under $15 \mathrm{Nm}$ torque are discussed with different mesh densities and element types. Table 1 shows the maximum strain in the $\mathrm{Y}$ direction when using the hexahedral element SOLID45 and the tetrahedral element Tet with different mesh densities.

Table 1. Analysis results based on different meshing

\begin{tabular}{|c|c|c|c|c|c|c|c|c|c|}
\hline Mesh method & \multicolumn{6}{|c|}{ Sweep(Hex Smart) } & \multicolumn{4}{c|}{ Free(Tes smart) } \\
\hline Density/mm & 5 & 6 & 7 & 8 & 9 & 10 & 6 & 7 & 8 \\
\hline Displacement $/ \mathrm{mm}$ & 0.218 & 0.215 & 0.204 & 0.203 & 0.213 & 0.249 & 0.166 & 0.113 & No convergence \\
\hline
\end{tabular}

(1)The displacement of the hexahedral element SOLID45 decreases gradually from 5 to 8 . This is because the analysis results deviated when the mesh density decreasing. When the mesh density is $5 \mathrm{~mm}$, the displacement is the largest $0.218 \mathrm{~mm}$, but the difference is only $0.003 \mathrm{~mm}$ comparing with density 6 .

(2)When Hexahedral element SOLID45 mesh density is changed from 8 to 10 , the displacement is increasing, because the analysis results are more and more deviated from the true value with the mesh density decreasing.

(3) The displacement gradient is much larger than that of hexahedron element when the mesh density of tetrahedron element is changed from 6 to 8 . It can not converge when the mesh density is 8 . It shows that different mesh density has great influence on the result of tetrahedral element analysis.
(4)When the mesh density is same, the displacement of the hexahedron element and the tetrahedron element is much different, and the difference is more than $0.05 \mathrm{~mm}$. This shows that the hexahedral mesh is more suitable for the important analysis place.

In summary, the hexahedron element can get a result closer to the true value than the tetrahedron element. So, for the contact nonlinear analysis, hexahedron element is used as far as possible, wedge element is used in the complex part of the model, and mesh is divided by free method. In order to reduce the calculation time, hexahedron element is selected and the mesh density is 6 . Hexahedral element meshed with density 10 is shown in Figure3. Tetrahedral element meshed with density 6 is shown in Figure4. 


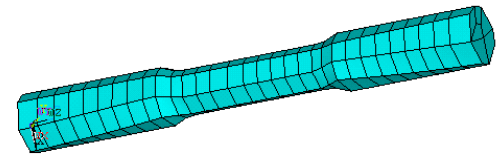

Figure 3. Hexahedral element density 10

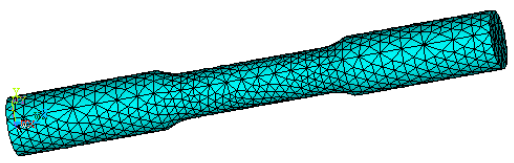

Figure 4. Tetrahedron element density 6

\subsection{Material properties}

The torsion bar is made of spring steel, and the input shaft and the output shaft are made of $40 \mathrm{Cr}$. The material properties are in table2.

Table 2. Material properties

\begin{tabular}{|c|c|c|c|c|}
\hline $\begin{array}{c}\text { Part } \\
\text { name }\end{array}$ & material & $\begin{array}{c}\text { Material } \\
\text { density/ } \\
\mathbf{k g} / \mathbf{m}^{\mathbf{3}}\end{array}$ & $\begin{array}{c}\text { Elastic } \\
\text { modulus/ } \\
\mathbf{G P a}\end{array}$ & $\begin{array}{c}\text { Possion's } \\
\text { ratio }\end{array}$ \\
\hline $\begin{array}{c}\text { Torsion } \\
\text { bar }\end{array}$ & $60 \mathrm{Si} 2 \mathrm{MnA}$ & 7850 & 213 & 0.29 \\
\hline $\begin{array}{c}\text { Input } \\
\text { shaft }\end{array}$ & $40 \mathrm{Cr}$ & 7850 & 206 & 0.3 \\
\hline $\begin{array}{c}\text { Output } \\
\text { shaft }\end{array}$ & $40 \mathrm{Cr}$ & 7850 & 206 & 0.3 \\
\hline
\end{tabular}

\subsection{Boundary conditions}

In the nonlinear analysis, only the key parts are needed to establish the contact surface, and the rest can be fixed by element coupling. The specific boundary conditions are

(1) Combine the outer diameter of the torsion bar and the inner diameter of the input shaft. The Ground resistance moment is simulated by the full coupling of the output shaft.

(2) By using contact nonlinear analysis, the contact surface attributes are defined for the contact parts of the torsion bar and the output shaft. The contacted parts of the torsion bar outer diameter are defined as CONTA173 contact surface, and the contacted parts of the output shaft inner diameter are defined as TARGE170.

(3) The contact stiffness factor FKN is 0.1.The friction coefficient of the contact part between the torsion bar and the output shaft is 0.11 (referring to the press-fit condition of steel and high-quality structural steel in material mechanics).

\subsection{Loading}

The external torque can not be applied by finite element analysis software [13].

Considering the safety factor, the maximum torque by hand is set as $15 \mathrm{Nm}$, and $1000 \mathrm{~N}$ force is applied to the tangent direction of the outer diameter circle of the input shaft.

\subsection{Analysis results}

The analysis results show that maximum stress is $5751 \mathrm{~N}$, the maximum tangential displacement is $0.22 \mathrm{~mm}$ and the strain analysis cloud chart are shown in Figure 5. But this is the applied point of the external load, which can not completely reflect the displacement of the torsion bar. The edge nodes of the middle section of the torsion bar are node255 and $\mathrm{Y}$ displacement is $0.255 \mathrm{~mm}$. The diameter of the middle section is $6 \mathrm{~mm}$, which shows that the angle of rotation is $\theta=\frac{\tau}{\gamma}=\frac{0.255}{3}=0.085$. If change to angle, it will be $4.9 \mathrm{deg}$. The delta angle is $1.1 \mathrm{deg}$ (6deg-4.9deg).

The main reason is the finite element analysis is based on the length $\left(L_{1}=18.8 \mathrm{~mm}\right)$ of the middle section of the torsion bar, and the theoretical analysis is based on the length $\left(\mathrm{L}_{\mathrm{a}}=22 \mathrm{~mm}\right)$ of the working section of the torsion bar, which inevitably results in the analysis results lower than the theoretical value. Then, 1.09 degrees can be obtained, when put the delta $4.2 \mathrm{~mm}\left(\mathrm{~L}_{2}-\mathrm{L}_{1}\right)$ into the formula (3). It is concluded that the difference between the theoretical analysis and the finite element analysis is only 0.01 degrees and the error is $0.1 \%$. 


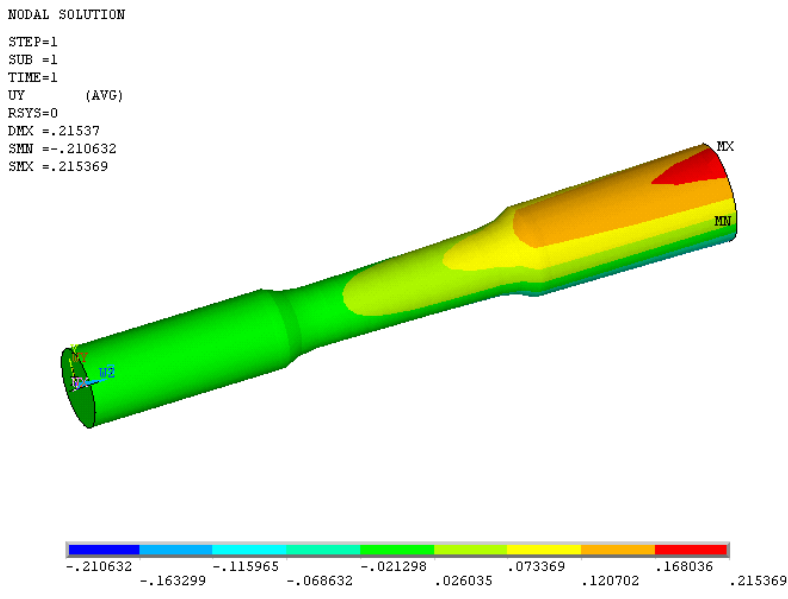

Figure 5. EPS analysis result

\section{Test validations}

According to the theoretical calculation results, the torsion bar structure and related parameters suitable for the target vehicle are designed, and the EPS system is developed. The system is tested by functional test bench, and EPS assistance is obtained.

According to the EPS test standard, the durability test is done, and the test results meet the requirements.

\section{Conclusions}

According to the specific requirements of the target vehicle, a new type of torsion bar structure without external spline is designed. The geometric model of EPS assembly is developed and the contact non-linear analysis is made. The analysis results meet the requirements. The structure is verified by the function and durability test.

\section{References}

1. Ji-Hoon Kim, Jae-Bok Song. Control logic for an electric power steering system using assist motor [J]. Mechatronics (S0957-4158), 2002, 12(3):447-459.

2. Y. TOKUMOTO, M. SHIBA, N. MAEDA, K. KOTAKA. Development of Next-Generation Steering Sensor for Electric Power Steering $[\mathrm{J}]$. Koyo Engineering Journal English Edition No. $165 \mathrm{E}(2004)$.

3. $\mathrm{F}$ Besson, $\mathrm{G}$ Ferraris, $\mathrm{M}$ Guingand,JPD Vaujany,Simulation of the Dynamic Behavior of Electric Power Steering System Using Dedicated
Finite Elements,Journal of System Design\&Dynamics, 3(3):429-440,2009.

4. Yuji Kozaki, GoroHirose, Shozo Sekiya. Electric Power steering [J]. Motor \&Control,1999:449-459

5. Didier ANGLEVIEL, Didier FRACHON, Gerald MASSON . Development of a Contactless Hall effect torque sensor for E1ectric Power Steering[J],SAE. 2006-0 1-0939.

6. Fang Shu-juan,Design and Calculation of Automotive Electric Power Steering System and Worm Drive,Mechanical Design, (12):52-55,2015.

7. LV Q T,XUE S, ZHU W Q,el al.. Pull-rod bent focusing mirror subassembly engineering analysis based on contact nonlinear analysis method[J]. SPIE,2009,7385:73850E_1-73850E_9.

8. Lv Qing-tao,Pull-rod bent focusing mirror system,Beijing,Graduate University of Chinese Academy of Science, 2010.

9. LEMANQUAND V , LEMANQUARD G. Magnetic differential torque sensor. IEEE Transactions on Magnetics. 1995 ,31 (6) :3188 - 3190.

10. Lv Qing-tao,Xue Song,Peng Zhong-qi,Zhu Wan-qian,Fu Yuan,Comparison of linear and contact non-linearity method for rod-beam compacting focusing mirror assembly,Optical and Precision Engineering,18(8):1842-1848,2010 .

11. M. Ben Rabha, M.F. Boujmil, M. Saadoun, B. Bessaïs, Eur. Phys. J. Appl. Phys. (to be published)

12. FF Mahmoud,AG EI-Shafei,MA Attia,AAA Pahman,Analysis of quasistatic frictional contact problems in nonliear viscoelasticity with large deformations, International Journal of Mechanical Science,66(4):109-119,2013.

13. Amassad,Fabre,Sofonea,A quasistatic viscoplastic contact problem with normal compliance and friction,Ima Journal of Applied Mathematics,69(5):463-482,2004. 